\title{
Enhancing the well-being of veterans using extended group-based nature recreation experiences
}

\author{
Jason Duvall, PhD; $\mathbf{1}^{*}$ Rachel Kaplan, $\mathbf{P h D}{ }^{\mathbf{2}}$ \\ ${ }^{1}$ Program in the Environment and ${ }^{2}$ School of Natural Resources and Environment, University of Michigan, Ann Arbor, MI
}

\begin{abstract}
Physical and mental health issues associated with military service persist as challenges for many veterans. This study draws on existing research showing the value of engaging in nature-based recreation to examine the effects of such experiences on veterans specifically. Four organizations, offering 12 different programs each lasting 4-7 d, were included in the study. Ninety-eight veterans were recruited and surveyed 1 wk before, 1 wk after, and approximately 1 mo after participating in these extended group-based outdoor experiences. In addition to background information, the survey instrument assessed changes in psychological well-being, social functioning, and life outlook. The results showed significant improvements in each of these domains 1 wk after the outdoor experience. Some improvements persisted over the next month, but to a lesser degree. The positive changes were particularly strong for veterans who initially reported more severe ongoing health issues. Overall, the findings suggest that extended group-based nature recreation experiences that bring veterans together can have significant positive effects on veterans struggling with serious health problems.
\end{abstract}

Key words: attentional functioning, mental health, mood, nature, outdoor recreation, quality of life, social functioning, survey research, well-being, wilderness.

\section{INTRODUCTION}

The transition back to civilian life is difficult for many veterans. In addition to coping with physical injuries, veterans often must deal with mental health issues, including depression, anxiety, and posttraumatic stress disorder (PTSD). These can take several months to mani- fest and last for extended periods, contributing to interpersonal conflict and substance abuse [1-3]. Managing ongoing mental health problems can be particularly challenging because of the negative perceptions veterans have about mental health treatment [4] and the uncertain efficacy of many conventional therapies [5].

Given this situation, it seems useful to explore nontraditional approaches that may enhance well-being and help veterans cope with transition. Nature-based recreation is one such alternative. While few studies have examined the effects of nature-based recreation on veterans specifically, both anecdotal and experimental data suggest that natural environments can be supportive of psychological health and well-being [6]. What is more, the unique training and experiences associated with military service may mean that this population would be quite willing to engage in extended wilderness recreation experiences with other veterans. Therefore, the focus of this study was to investigate the benefits associated with exposure to these multiday group-based outdoor excursions with other non-Active Duty military personnel.

\footnotetext{
Abbreviations: $A R T=$ attention restoration theory, IRB = institutional review board, PTSD = posttraumatic stress disorder, TBI = traumatic brain injury.

*Address all correspondence to Jason Duvall, PhD; Program in the Environment, University of Michigan, 1120 Undergraduate Science Building, 204 Washtenaw Ave, Ann Arbor, MI 48109-2215; 734-904-4076.

Email: duvalli@umich.edu

http://dx.doi.org/10.1682/JRRD.2013.08.0190
} 
Note that portions of this article are drawn from a research report that was created for the Sierra Club Foundation, the sponsor of this research.

\section{BACKGROUND}

The idea that nature has therapeutic benefits is hardly new. In the latter part of the 19th century, getting out into nature was a standard medical treatment for dealing with issues such as emotional distress and mental exhaustion [7]. However, only in the last several decades have researchers begun to rigorously investigate the effect that contact with nature has on human health and well-being. This effort has resulted in a substantial growth in empirical research, with numerous studies documenting the diversity of benefits related to exposure to natural environments. Reviews of this empirical literature are plentiful [8-16]. Findings from this work suggest that even relatively short exposures to natural environments can have a significant effect on psychological health, leading to improvements in mood [17-18], attentional functioning [19-24], coping abilities [25], and overall well-being [26].

Attention restoration theory (ART) hypothesizes that natural environments enhance psychological well-being by enabling the recovery of a limited and fatigable cognitive resource necessary for self-regulation and cognitive inhibition [6,27]. According to ART, everyday activities that involve focusing on uninteresting stimuli and/or persisting in the face of external and internal distractions require an effortful form of attention. The capacity to voluntarily employ or direct such attention is limited, however, and as this capacity becomes depleted, it becomes increasingly difficult to remain focused, keep distractions at bay, and regulate behavior. In order to regain the capacity to direct attention, one must let it rest. Natural settings seem particularly well equipped to facilitate this restorative process because they are filled with innately fascinating and aesthetically appealing stimuli. The softly fascinating content found in nature may also facilitate reflection [28] and help individuals cope more effectively with unresolved issues as well as feelings of confusion and self-doubt that can interfere with successful functioning [29].

Studies examining the effect of extended group outdoor recreation experiences are consistent with the ideas proposed by ART. For instance, research on women who engaged in extended outdoor recreation found that participants reported greater mental clarity, spiritual growth, and a stronger sense of connection to others after the experience [30-31]. Similar results have been described by teenagers participating in organized backcountry recreation programs, who reported feeling less confused, more hopeful about the future, increased self-esteem, and a greater sense of "wholeness" [27,32-34].

Several studies have examined the effect of group outdoor recreation experiences on veterans specifically. Hyer et al. recruited veterans diagnosed with PTSD to participate in a $5 \mathrm{~d}$ Outward Bound course that included activities such as rock climbing, hiking, and whitewater rafting [35]. While participants did not report a reduction in PTSD symptoms, there was evidence of improvements in emotional control, self-esteem, and social connectedness. Gelkopf et al. examined the effect of a yearlong weekly sailing nature adventure experience on military veterans with PTSD [36]. In comparison to a waitlist control group, veterans in the sailing intervention reported significant reductions in PTSD symptomatology and depression as well as improvements in life functioning and feelings of hope. Lundberg et al. studied whether veterans with disabilities such as traumatic brain injury (TBI), PTSD, and depression experienced benefits from participating in $5 \mathrm{~d}$ outdoor recreation programs that included activities ranging from fly-fishing to Nordic skiing [37]. Participants involved in these programs reported significant reductions in tension, depression, and anger as well as slight improvements in quality of life immediately following the experience.

While these findings are encouraging, drawing definitive conclusions about the effect of extended group outdoor recreation experiences is difficult because of several inherent methodological issues. First, many of these studies rely on relatively small sample sizes, a limitation that is hard to avoid because participation is necessarily restricted in terms of group size. Maintaining small groups, however, has many logistic and social advantages in terms of the participants' experiences. Another potentially significant challenge involves the lack of consistency among programs. The great variation in the length and structure of programs as well as the unique social dynamics of each outdoor recreation group is likely to influence what each participant takes away from the experience. The lack of a control group in many studies also makes it difficult to be sure changes are due to the outdoor recreation experience itself. A final challenge involves determining whether improvements in wellbeing and functioning are sustained over the longer term. 
The practical and logistical problems associated with longitudinal research, however, often mean that effects can only be assessed immediately following the outdoor recreation experience.

Given these challenges, one might question the usefulness of this work; but, all research is necessarily constrained and limited in terms of the inferences that can be drawn. Yet knowledge builds from such limited information and we can still find meaning despite these shortcomings. With this in mind, the purpose of the present study was to build on the existing empirical evidence suggesting that group-based nature recreation experiences can be beneficial. While the study faces many of the inherent limitations just described, it also provides additional clues about potential benefits that veterans can derive from participating in multiday group wilderness experiences with respect to psychological well-being, social functioning, and life outlook. Investigating these outcomes immediately following the outdoor experience does have advantages and could reduce attrition in response rate, but an important goal of this research was to examine whether changes were sustained over time. As a result, this study used a repeated-measure design to assess participants at three different points: 1 wk before the nature recreation experience, $1 \mathrm{wk}$ after the experience, and 1 mo after the experience.

\section{METHODS}

\section{Participants}

The Sierra Club's Military Families and Veterans Initiative and four partner organizations recruited 98 veterans by posting announcements about the extended group outdoor recreation programs in veterans' newsletters, on partner organization Web sites, and on various social media sites. Information about these programs was also distributed by sending flyers and email announcements to Department of Veterans Affairs facilities, military installations, and veterans' organizations near locations where programs were being offered. After applying through the partner organizations, participants were asked to complete an initial pretest survey. Participation was open to non-Active Duty military personnel. While program participation did require a baseline level of good physical fitness, accommodations were made for veterans with physical and/or mental disabilities and these individuals were encouraged to apply. Pretest respondents were pre- dominantly male, between 30 and $49 \mathrm{yr}$ of age, and unemployed (Table 1). The vast majority of the participants $(78 \%)$ indicated that it had been $10 \mathrm{yr}$ or less since their last Active Duty assignment, and almost half the group (44\%) indicated that their last assignment had occurred within the last 5 yr. More than half the sample (54\%) reported that they often experienced physical or mental health issues that interfered with their everyday life. Participants also reported struggling with a number of specific psychological and behavioral issues such as

Table 1.

Characteristics of participants based on pretest survey responses.

\begin{tabular}{lc}
\hline \multicolumn{1}{c}{ Characteristic } & \% \\
\hline Sex & \\
Female & 21.6 \\
Male & 78.4 \\
Age (yr) & \\
20-29 & 20.7 \\
30-39 & 27.1 \\
40-49 & 31.5 \\
50 and over & 20.7 \\
Education & \\
High School & 7.1 \\
Some College & 45.9 \\
2-Year Degree & 11.2 \\
4-Year Degree & 23.5 \\
Postgraduate Degree & 12.2 \\
Employed & \\
No & 52.6 \\
Yes & 47.4 \\
Years Since Last Active Duty & \\
0-5 & \\
6-10 & 44.1 \\
>10 & 34.4 \\
Physical Disabilies that Might Interfe with Extended & 21.5
\end{tabular}

Physical Disabilities that Might Interfere with Extended Outdoor Recreation Experience

$\begin{array}{ll}\text { No } & 60.2\end{array}$

Yes

39.8

Treated for Mental Health/Substance Abuse Issues Since Last Deployment

No 29.6

Yes $\quad 70.4$

How Often Physical and Mental Health Issues Get in Way of Everyday Life

Never or Rarely 27.5

Sometimes $\quad 18.4$

Often or Very Often $\quad 54.1$

Previous Experience with Organized Group Outdoor Recreation No $\quad 59.8$

\begin{tabular}{ll} 
Yes & 40.2 \\
\hline
\end{tabular} 
PTSD (46\%), depression (27\%), anxiety (24\%), alcohol and substance abuse (19\%), and TBI (14\%). In addition, most participants reported having no previous experience with organized group outdoor experiences. Only 73 of those completing the initial survey participated in any of the outings. Of this group, 54 veterans completed the posttest survey (74\% return rate) and 31 completed the follow-up survey (42\% return rate). Comparisons between pretest, posttest, and follow-up survey respondents showed no significant differences with respect to background characteristics.

\section{Program Description}

The Sierra Club's Military Families and Veterans Initiative and four partner organizations sponsored and administered the extended group outdoor recreation experiences. In total, these organizations offered 12 different programs at deeply discounted rates or at no charge to veterans. Descriptions of these organizations and programs are provided in Appendix 1 (available online only). Group size ranged between 5 and 10 participants and consisted mainly of military veterans who did not know one another before participating in this experience. The programs, held during spring through early fall of 2012, involved between 4 and $7 \mathrm{~d}$ of wilderness experience emphasizing various outdoor activities, such as backpacking, canoeing, whitewater rafting, and fly-fishing. All the programs included activities and exercises focused on developing wilderness recreation skills such as backcountry navigation and water safety.

All the programs featured the recreational component in the context of enhancing the health and well-being of veterans. Although in most instances psychologists were onsite, the majority of programs did not include any formal, structured psychological counseling or therapy. According to program debriefing documents, 2 of the 12 programs included some structured therapeutic activities such as journaling, voluntary large and small group therapy sessions, and team-building exercises intended to enhance trust and communication. Other programs, however, also reported engaging in informal group discussions about life challenges and the struggles associated with military service as well as wilderness skills activities that emphasized team building. Given this mixture of approaches, it would be misleading to classify programs into recreational or therapeutic categories and inappropriate to examine differences among groups. The small sample sizes of the programs and incompleteness of the posttest and follow-up data also preclude between-group statistical comparisons.

In order to establish a baseline and examine changes over time, the partner organizations asked participants to complete a pretest survey approximately $1 \mathrm{wk}$ before the outdoor recreation experience, a posttest survey $1 \mathrm{wk}$ after the experience, and a follow-up survey approximately 3 to 4 wk after the outdoor program. The partner organizations, however, did not have access to participants' survey responses and the research team had no identifying information about the participants. In light of these measures, the university-affiliated institutional review board (IRB) deemed the study exempt from IRB oversight.

\section{Measures}

A number of established and validated survey-based instruments were used to investigate changes in areas related to psychological well-being, social functioning, and life outlook. In each case, veterans responded by rating the items using a 5-point scale.

\section{Psychological Well-Being}

Psychological well-being was assessed by examining perceived stress, attentional functioning, and affective experience. Perceived stress was measured using a 4-item version of the Perceived Stress Scale [38], asking about the frequency of feeling unable to cope with general life stress ("never" to "very often"). Attentional functioning was assessed using a modified version of the Attentional Functioning Index [39], which is designed to measure perceived effectiveness in a variety of everyday activities that require self-regulation and executive control [4041]. Participants were asked to rate how well they felt they had been functioning in nine of these areas ("not very well" to "extremely well”). The affective experience measure asked participants to rate the degree to which they experienced each of 22 positive and negative emotions ("never" to "always"). This measure was developed by adapting items from the Positive and Negative Affect Schedule [42].

\section{Social Functioning and Life Outlook}

Measures of social functioning included a 3-item modified version of the UCLA Loneliness Scale [43] and a 3-item modified version of the Social Connectedness Scale [44]. Both of these measures ask about frequency of feeling socially isolated and alone ("never" to "very 
often”). In addition, participants were asked to rate how much they agreed with a number of statements designed to measure how life was going right now and what they expected for the future ("strongly disagree" to "strongly agree”). This 9-item measure of life outlook was generated by adapting items from the State Hope Scale [45] and the Seeking of Noetic Goals Test [46].

\section{Demographics and Background}

The pretest survey included demographic questions (e.g., age, sex, education, employment) as well as questions about veterans' prior military service, history of physical and mental health conditions, and prior experience with organized group outdoor recreation.

\section{Statistical Analysis}

In order to assess construct validity and identify common themes, separate factor analyses using principal-axis factoring with Varimax rotation were conducted on pretest responses to each of the psychological well-being, social functioning, and life outlook measures. Factor structures were based on item loadings of at least 0.45 , Eigenvalues greater than 1.0, and alpha coefficients of at least 0.55 . Items loading on more than one factor were excluded.

Linear mixed models were used to examine changes in psychological well-being, social functioning, and life outlook over time. This method was chosen because it allows for analyzing correlated observations that are measured repeatedly under different conditions [47]. The linear mixed model also allows inclusion of missing data, giving this approach a distinct advantage over more traditional longitudinal and repeated-measures analysis methods, which remove individuals who do not have data at all time points [47].

To account for possible variation between individuals, a random coefficient model using a random intercept was used to investigate all survey data. In all cases, a topdown model building strategy was used, which involved starting with the fixed effects of all theoretically relevant covariates and interactions and removing nonsignificant fixed effects until the best overall fit was achieved [47]. As a result, pretest variables related to employment and the presence of physical or mental health issues interfering with everyday life were controlled for in all mixed models. Once an appropriate fit was determined, the mixed model analysis was used to examine changes over time by conducting a series of pairwise comparisons based on estimated marginal means.

\section{RESULTS}

\section{Development of Measures}

Appendix 2 (available online only) includes the items for each of the measures, based on the factor analyses. The alpha coefficients, also included in Appendix 2, ranged between 0.79 and 0.93 . Factor analyses of the Perceived Stress Scale and the Attentional Functioning Index confirmed that these two measures were part of distinct and reliable factors related to one's ability to cope with life stress and effectively function. Analysis of the affective experience items yielded three distinct factors: "positive affect" (8 items), "negative affect" (10 items), and "tranquility" (3 items related to feelings of relaxation and contentment). One item, "alert," failed to load on any factor and was dropped. Correlations among the five psychological well-being factors ranged between 0.57 and 0.73 . Given the high internal consistency for each measure and their focus on different dimensions of well-being, they were kept as separate measures.

The high correlation $(0.76)$ between the modified versions of the UCLA Loneliness Scale and the Social Connectedness Scale and their similarity in terms of content led to a combined measure, Social Functioning. Factor analysis confirmed that combining these subscales resulted in a reliable and coherent measure. Likewise, the State Hope Scale and the Seeking of Noetic Goals Test were combined into a single measure of Life Outlook because they also assessed very similar constructs and factor analysis confirmed that this combined measure represented a reliable and coherent construct.

\section{Psychological Well-Being}

Analyses using the linear mixed models to examine changes in psychological well-being over time indicate that participants experienced a number of significant improvements (Table 2). In particular, participants' responses at posttest, as compared with the baseline responses, were significantly different in the expected direction for four of the five measures. The ratings were higher on attentional functioning, positive affect, and tranquility and significantly lower with respect to negative affect. For perceived stress, by contrast, there was little change over time. This may indicate that veterans' percep- 
Table 2.

Psychological well-being of participants over time.

\begin{tabular}{|c|c|c|c|c|c|}
\hline \multirow{2}{*}{ Measure } & \multicolumn{3}{|c|}{$\begin{array}{c}\text { Mean Psychological Well-Being } \\
\text { ( } n, \text { Estimated Marginal Mean [SE]) }\end{array}$} & \multicolumn{2}{|c|}{$\begin{array}{c}\text { Change in Psychological Well-Being } \\
\text { (Mean Difference, } p \text {-Value) }\end{array}$} \\
\hline & Pretest & Posttest & Follow-Up & $\begin{array}{c}\text { Pretest to } \\
\text { Posttest }\end{array}$ & $\begin{array}{l}\text { Pretest to } \\
\text { Follow-Up }\end{array}$ \\
\hline Perceived Stress* & $95,2.54(0.07)$ & $50,2.46(0.09)$ & $28,2.41(0.11)$ & $-0.09,0.92$ & $-0.14,0.64$ \\
\hline Attentional Functioning ${ }^{\dagger}$ & 93, $2.78(0.08)$ & $50,3.13(0.10)$ & $28,3.04(0.13)$ & $0.34,0.001$ & $0.26,0.09$ \\
\hline Positive Affect ${ }^{\ddagger}$ & 93, $3.11(0.07)$ & 50, 3.47 (0.09) & $28,3.39(0.11)$ & $0.36,<0.001$ & $0.27,0.03$ \\
\hline $\begin{array}{l}{ }^{*} \text { Based on Perceived Stress Scal } \\
{ }^{\dagger} \text { Based on Attentional Functioni } \\
{ }^{\ddagger} \text { Based on Positive and Negative } \\
\text { SE = standard error. }\end{array}$ & $\begin{array}{l}\text { ex [39]. } \\
\text { t Schedule [42]. }\end{array}$ & & & & \\
\hline
\end{tabular}

tions about their ability to cope with general life stressors are fairly stable and that changing these perceptions may require more specialized and targeted interventions.

Given the relatively brief nature of the outdoor programs, it would be reasonable to expect that the improvements in attentional functioning, positive affect, negative affect, and tranquility would largely disappear at followup (i.e., several weeks after the outdoor experience). However, there is some evidence of enduring effects. This pattern is strongest for positive affect, for which participants reported a significant improvement from baseline to follow-up. Although not significant, the $p$-levels $<$ 0.10 suggest some sustained improvement in attentional functioning, negative affect, and tranquility from baseline to follow-up.

While these results provide an overall picture of how the extended outdoor recreation experience influenced well-being, the linear mixed model analyses also indicate that the improvements differed depending on the severity of participants' physical or mental health issues. Based on their response to the pretest question "How often do you experience physical or mental health issues that get in the way of your everyday life," participants were categorized as "infrequent" ("never," "rarely," or "sometimes" responses) and "frequent" ("often" or "very often" responses). It is worth noting that more than half the sample (54\%) falls into the "frequent" category and that this group also reported high rates of unemployment (69\%) and treatment for mental health or substance abuse issues (94\%). As would be expected, the baseline scores for the two groups are significantly different (Table 3).

Results of the linear mixed models indicate no significant changes in any of the psychological well-being measures for the participants who infrequently experienced everyday health issues, although the pattern of change is in the expected direction (Table 3). In contrast, participants in the "frequent" category showed significant improvements in attentional functioning, positive affect, negative affect, and tranquility from pretest to posttest. While follow-up results should be interpreted with caution because of the relatively small sample sizes, there is some evidence that the psychological well-being of participants who more frequently experienced everyday health issues continued to improve over the long term. These participants reported a significant increase in feelings of tranquility and significant declines in both perceived stress and negative affect at follow-up. These results suggest that veterans with more severe physical or mental health problems may experience positive wellbeing effects even 1 mo after participating in an extended group outdoor recreation experience.

\section{Social Functioning and Life Outlook}

As shown in Table 4, participants experienced significant improvements from pretest to posttest on both social functioning and life outlook. This indicates that the extended group outdoor recreation experience was associated with greater feelings of social connectedness, fewer feelings of loneliness and isolation, and a more positive overall assessment of life circumstances. As with psychological well-being, there was a trend indicating that these improvements in social function and life outlook persisted 1 mo later at follow-up.

Once again, the linear mixed model results indicate the importance of considering physical or mental health issues that interfere with daily life (Table 5). At baseline, 
Table 3.

Psychological well-being of participants based on frequency of everyday health issues.

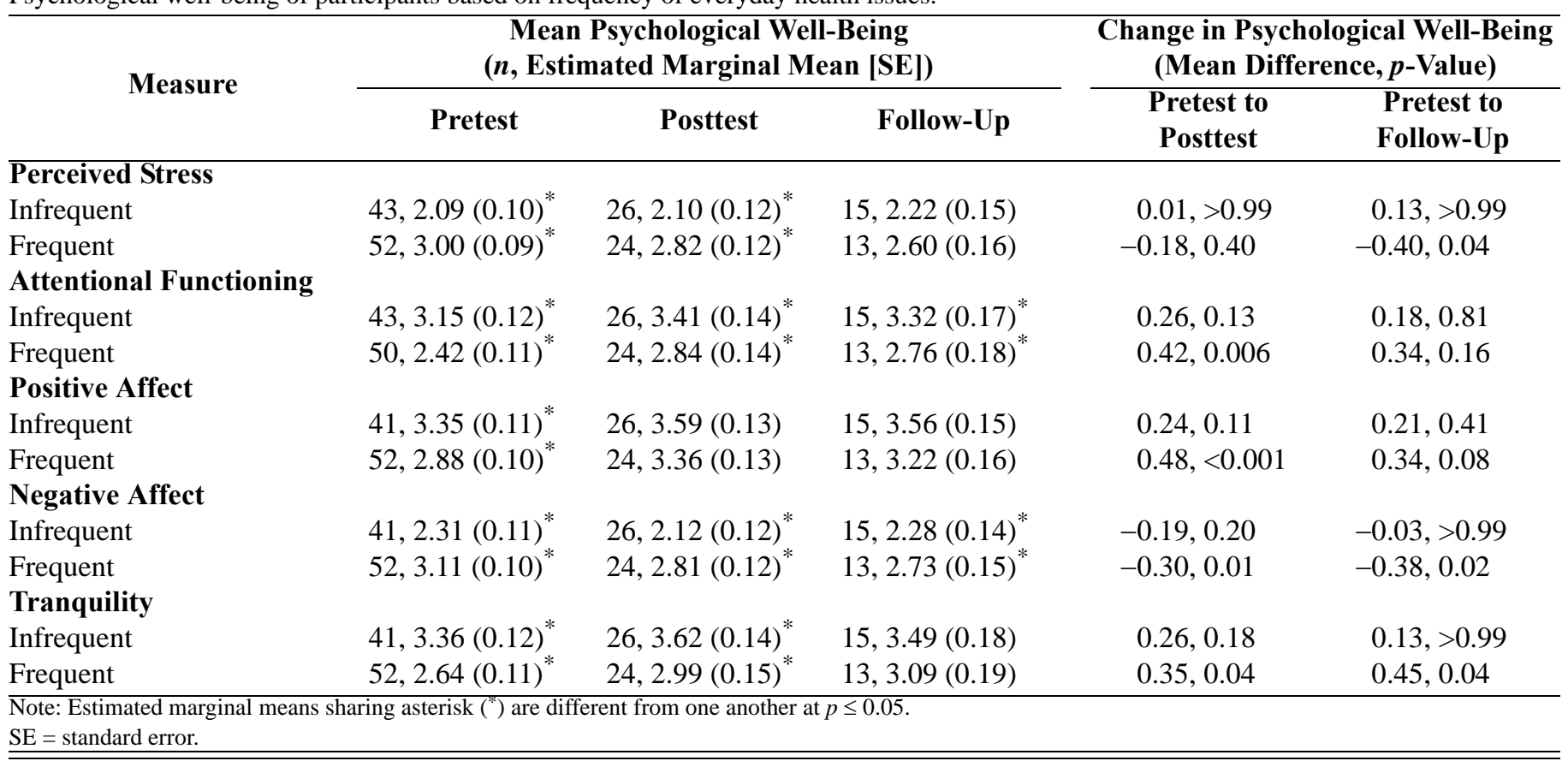

Table 4.

Social functioning and life outlook of participants over time.

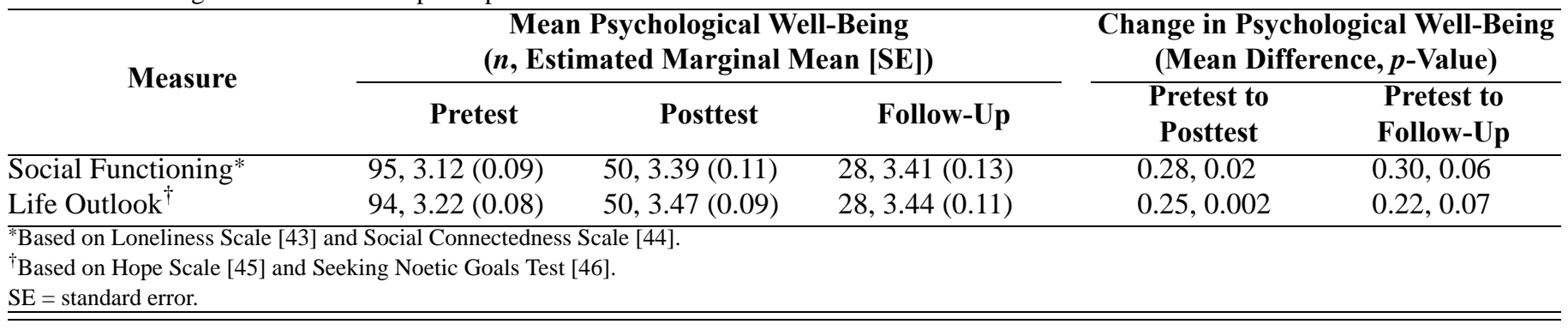

the two groups were significantly different with respect to both the social functioning and life outlook measures, and the pattern of changes over time closely parallel the psychological well-being results. For participants who indicated that they infrequently experienced everyday health issues, the results showed no significant changes in either social functioning or life outlook. On the other hand, participants who frequently experienced these issues reported significant improvements in both social functioning and life outlook when pretest and posttest responses were compared. Furthermore, the comparison between baseline levels and follow-up ratings show sustained improvement in social functioning scores, although not for the outlook scores. The small sample size at follow-up again means that one should not overstate these results; however, these findings reinforce the possibility that veterans with more serious health issues may find extended group wilderness experiences especially beneficial.

\section{DISCUSSION}

The purpose of this research was to explore the benefits associated with exposure to multiday group-based outdoor experiences for non-Active Duty military personnel. Given the serious challenges facing many military veterans, there is reason to initially be skeptical 
JRRD, Volume 51, Number 5, 2014

Table 5.

Change in social functioning and life outlook based on frequency of everyday health issues.

\begin{tabular}{|c|c|c|c|c|c|}
\hline \multirow{2}{*}{ Measure } & \multicolumn{3}{|c|}{$\begin{array}{c}\text { Mean Psychological Well-Being } \\
\text { ( } n \text {, Estimated Marginal Mean [SE]) }\end{array}$} & \multicolumn{2}{|c|}{$\begin{array}{c}\text { Change in Psychological Well-Being } \\
\text { (Mean Difference, } p \text {-Value) }\end{array}$} \\
\hline & Pretest & Posttest & Follow-Up & $\begin{array}{c}\text { Pretest to } \\
\text { Posttest }\end{array}$ & $\begin{array}{l}\text { Pretest to } \\
\text { Follow-Up }\end{array}$ \\
\hline \multicolumn{6}{|l|}{ Social Functioning } \\
\hline Infrequent & $43,3.57(0.13)^{*}$ & $26,3.76(0.15)^{*}$ & $15,3.60(0.18)$ & $0.19,0.50$ & $0.03,>0.99$ \\
\hline Frequent & $52,2.67(0.12)^{*}$ & $24,3.03(0.15)^{*}$ & $13,3.23(0.19)$ & $0.36,0.03$ & $0.56,0.007$ \\
\hline \multicolumn{6}{|l|}{ Life Outlook } \\
\hline Frequent & $51,2.90(0.11)^{*}$ & $24,3.21(0.13)^{*}$ & $12,3.13(0.16)^{*}$ & $0.31,0.01$ & $0.23,0.29$ \\
\hline
\end{tabular}

about whether engaging in a relatively short nonclinical outdoor recreation program would have a significant effect, even $1 \mathrm{wk}$ after the experience. However, results of this study indicate that veterans who participated in these programs did, in fact, experience a number of important benefits with respect to psychological wellbeing, social functioning, and life outlook.

Study participants reported significant improvements in multiple aspects of psychological well-being $1 \mathrm{wk}$ after the outdoor intervention. The improvements in attentional functioning and emotional tone (increases in positive affect and feelings of tranquility; decreases in negative affect) are consistent with existing research on the restorative effects of natural environments and are noteworthy given that mental health problems, such as PTSD, have been associated with impairments in executive functioning and an increased risk of depression [4849]. While psychological well-being seemed to decline slightly over time, the results suggest that the improvements in well-being were sustained even 1 mo after the outdoor experience, especially with respect to positive affect. Participants also reported significant improvements in both social functioning and life outlook $1 \mathrm{wk}$ after the intervention. Again, there was some indication that these improvements persisted over the long term. The finding that participation in these group outdoor recreation experiences was associated with greater feelings of social connectedness and more optimistic attitudes about current life circumstances is particularly compelling when one considers that interpersonal conflict and feelings of hopelessness are not uncommon problems among veterans $[2,50]$.

Perhaps more importantly, the findings suggest that these extended group-based nature recreation programs may have a bigger effect on veterans most in need of help. Participants who reported experiencing more severe everyday health problems before the intervention were much more likely to report significant improvements in psychological well-being, social functioning, and life outlook 1 wk after the program. In many cases, these improvements were substantial, with the magnitude of change often 1.5 times that of participants' reporting less serious health issues. The small sample size at follow-up makes it difficult to know whether the improvements experienced by this group can be sustained over longer periods of time. However, the findings with respect to the reduction in perceived stress and negative affect, as well as the increases in feelings of tranquility and social functioning, suggest such benefits might persist and even continue to increase for several weeks after the intervention.

\section{LIMITATIONS AND FUTURE DIRECTIONS}

Although these findings are encouraging and are consistent with previous work suggesting that multiday group-based nature recreation experiences can have significant positive effects, there are limitations of this study that should be acknowledged and used to inform future research. The ideal research approach of random assignment and large enough groups to permit examination of the effects of particular activities are incommensurate with the intentions of these recreation experiences and the veterans' motivations to participate. The study, thus, consisted of a self-selected nonrandom sample, making it difficult to determine how generalizable these results are to the larger veteran population. The relatively small sample size, especially at follow-up, also means that the 
results suggesting that benefits might be sustained over the long term should be interpreted with caution. While individuals who responded to the follow-up survey were similar to nonresponders in terms of demographic variables, it is possible that follow-up results may not be representative of all participants.

A further limitation is related to the very nature of the outdoor recreation programs that are the basis for the intervention. These are necessarily distinct along many dimensions. They vary in program length, type of outdoor recreation, group size, group composition, and many other structural respects. These variations and the relatively small number of participants in each outing make it difficult to know how much the specific program features affect outcomes like well-being or social functioning. While the programs shared many common features, it is possible that different recreational activities lead to different outcomes because they do a better job of promoting reflection or are more supportive of social interaction. Likewise, programs that incorporate more structured therapeutic activities with smaller groups may be particularly effective for veterans with more serious mental health issues. Even with similar programs, however, the dynamics among participants sharing the experience could also have strong effects. Ideally, a more systematic investigation controlling for some of these issues would allow comparison of outcomes associated with participation in different types of programs.

The results also raise questions about the conditions under which benefits are more likely to be sustained over longer time periods. For instance, future studies may examine whether longer interventions lead to more lasting benefits and whether benefits could be sustained more easily if extended group-based wilderness programs were paired with more regular single or half-day group-based nature recreation experiences. It may be particularly interesting to investigate whether combining outdoor recreation experiences with more conventional therapeutic approaches would lead to even larger and more substantial changes in well-being given recent studies exploring the effects of these types of programs on individuals with depression, TBI, and suicidal tendencies [51-54].

\section{CONCLUSIONS}

Taken together, results of this study suggest that extended group-based nature recreation experiences can have significant positive effects on veterans. These findings also indicate that veterans with more severe health issues may find these programs especially beneficial. The positive outcomes associated with these programs can partly be attributed to spending time in restorative natural environments; however, there are a number of other aspects of this experience that likely play an important role. The outings permitted veterans to spend several days with other veterans in an outdoor setting pursuing challenging tasks. Personal challenge, companionship with other veterans, and living outdoors are all likely to resonate with experiences these participants had while in the military. Although more research is clearly needed, using extended group-based outdoor recreation programs to enhance the psychological health and well-being of veterans seems to be a promising approach.

\section{ACKNOWLEDGMENTS}

\section{Author Contributions:}

Study concept and design: J. Duvall, R. Kaplan. Acquisition of data: J. Duvall, R. Kaplan.

Analysis and interpretation of data: J. Duvall, R. Kaplan.

Financial Disclosures: The authors have declared that no competing interests exist.

Funding/Support: This material was based on work supported by the Sierra Club Foundation (project number N014217).

Additional Contributions: This research would not have been possible without support from the Sierra Club Military Families and Veterans Initiative, Wilderness Inquiry, Wasatch Adaptive Sports, Higher Ground Sun Valley, and the Women's Wilderness Institute.

Institutional Review: The university-affiliated IRB deemed the study exempt from IRB oversight.

Participant Follow-Up: The authors do not plan to inform participants of the publication of this study because contact information is unavailable.

\section{REFERENCES}

1. Seal KH, Metzler TJ, Gima KS, Bertenthal D, Maguen S, Marmar CR. Trends and risk factors for mental health diagnoses among Iraq and Afghanistan veterans using Department of Veterans Affairs health care, 2002-2008. Am J Public Health. 2009;99(9):1651-58. [PMID:19608954] http://dx.doi.org/10.2105/AJPH.2008.150284

2. Milliken CS, Auchterlonie JL, Hoge CW. Longitudinal assessment of mental health problems among active and reserve component soldiers returning from the Iraq war. JAMA. 2007;298(18):2141-48. [PMID:18000197] http://dx.doi.org/10.1001/jama.298.18.2141 
3. Dekel R, Monson CM. Military-related post-traumatic stress disorder and family relations: Current knowledge and future directions. Aggress Violent Behav. 2010; 15:303-9. http://dx.doi.org/10.1016/j.avb.2010.03.001

4. Hoge CW, Castro CA, Messer SC, McGurk D, Cotting DI, Koffman RL. Combat duty in Iraq and Afghanistan, mental health problems, and barriers to care. N Engl J Med. 2004; 351(1):13-22. [PMID:15229303] http://dx.doi.org/10.1056/NEJMoa040603

5. Kitchiner NJ, Roberts NP, Wilcox D, Bisson JI. Systematic review and meta-analyses of psychosocial interventions for veterans of the military. Eur J Psychotraumatol. 2012;3.

6. Kaplan S. The restorative benefits of nature: Toward an integrative framework. J Environ Psychol. 1995;15:169-82. http://dx.doi.org/10.1016/0272-4944(95)90001-2

7. Schuster DG. MSJAMA. Neurasthenia and a modernizing America. JAMA. 2003;290(17):2327-28. [PMID:14600195] http://dx.doi.org/10.1001/jama.290.17.2327

8. Abraham A, Sommerhalder K, Abel T. Landscape and well-being: A scoping study on the health-promoting impact of outdoor environments. Int J Public Health. 2010; 55(1):59-69. [PMID:19768384] http://dx.doi.org/10.1007/s00038-009-0069-z

9. Frumkin H. Beyond toxicity: Human health and the natural environment. Am J Prev Med. 2001;20(3):234-40. [PMID:11275453] http://dx.doi.org/10.1016/S0749-3797(00)00317-2

10. Maller C, Townsend M, Pryor A, Brown P, St Leger L. Healthy nature healthy people: 'contact with nature' as an upstream health promotion intervention for populations. Health Promot Int. 2006;21(1):45-54. [PMID:16373379] http://dx.doi.org/10.1093/heapro/dai032

11. Pretty J. How nature contributes to mental and physical health. Spiritual Health Int. 2004;5:68-78. http://dx.doi.org/10.1002/shi.220

12. Stigsdotter UK, Palsdottir AM, Burls A, Chermaz A, Ferrini F, Grahn P. Nature-based therapeutic interventions. In: Nilsson K, Sangster M, Gallis C, Hartig T, De Vries S, Seeland $\mathrm{K}$, Schipperijn J, editors. Forests, trees and human health. New York (NY): Springer; 2011. p. 309-42.

13. Ward Thompson C. Linking landscape and health: The recurring theme. Landsc Urban Plan. 2011;99:187-95. http://dx.doi.org/10.1016/j.landurbplan.2010.10.006

14. Bowler DE, Buyung-Ali LM, Knight TM, Pullin AS. A systematic review of evidence for the added benefits to health of exposure to natural environments. BMC Public Health. 2010;10:456. [PMID:20684754] http://dx.doi.org/10.1186/1471-2458-10-456

15. Bratman GN, Hamilton JP, Daily GC. The impacts of nature experience on human cognitive function and mental health. Ann N Y Acad Sci. 2012;1249:118-36.

\section{[PMID:22320203]}

http://dx.doi.org/10.1111/j.1749-6632.2011.06400.x

16. Annerstedt M, Währborg P. Nature-assisted therapy: Systematic review of controlled and observational studies. Scand J Public Health. 2011;39(4):371-88.

[PMID:21273226]

http://dx.doi.org/10.1177/1403494810396400

17. Hull RB, Michael SE. Nature-based recreation, mood change, and stress restoration. Leis Sci. 1995;17:1-14.

http://dx.doi.org/10.1080/01490409509513239

18. Hartig T, Evans GW, Jamner LD, Davis DS, Garling T. Tracking restoration in natural and urban field settings. J Environ Psychol. 2003;23:109-23.

http://dx.doi.org/10.1016/S0272-4944(02)00109-3

19. Berman MG, Jonides J, Kaplan S. The cognitive benefits of interacting with nature. Psychol Sci. 2008;19(12):1207-12. [PMID:19121124]

http://dx.doi.org/10.1111/j.1467-9280.2008.02225.x

20. Cimprich B, Ronis DL. An environmental intervention to restore attention in women with newly diagnosed breast cancer. Cancer Nurs. 2003;26(4):284-92, quiz 293-94. [PMID:12886119] http://dx.doi.org/10.1097/00002820-200308000-00005

21. Kuo FE. Coping with poverty: Impacts of environment and attention in the inner city. Environ Behav. 2001;33:5-34. http://dx.doi.org/10.1177/00139160121972846

22. Taylor AF, Kuo FE, Sullivan WC. Coping with ADD: The surprising connection to green play settings. Environ Behav. 2001;33:54-77. http://dx.doi.org/10.1177/00139160121972864

23. Wells NM. At home with nature: Effects of "greenness" on children's cognitive functioning. Environ Behav. 2000;32: 775-95. http://dx.doi.org/10.1177/00139160021972793

24. Berto R. Exposure to restorative environments helps restore attentional capacity. J Environ Psychol. 2005;25: 249-59. http://dx.doi.org/10.1016/j.jenvp.2005.07.001

25. Ottosson J, Grahn P. The role of natural settings in crisis rehabilitation: How does the level of crisis influence the response to experiences of nature with regard to measures of rehabilitation? Landsc Res. 2008;33:51-70. http://dx.doi.org/10.1080/01426390701773813

26. Kaplan R. The nature of the view from home: Psychological benefits. Environ Behav. 2001;33:507-42. http://dx.doi.org/10.1177/00139160121973115

27. Kaplan R, Kaplan S. The experience of nature: A psychological perspective. Cambridge (UK): Cambridge University; 1989.

28. Herzog TR, Black AM, Fountaine KA, Knotts DJ. Reflection and attentional recovery as distinctive benefits of restorative environments. J Environ Psychol. 1997;17:165-70. http://dx.doi.org/10.1006/jevp.1997.0051 
29. Kaplan S, Berman M. Directed attention as a common resource for executive functioning and self-regulation. Perspect Psychol Sci. 2010;5:43-57. http://dx.doi.org/10.1177/1745691609356784

30. Pohl SL, Borrie WT, Patterson ME. Women, wilderness, and everyday life: A documentation of the connection between wilderness recreation and women's everyday lives. J Leis Res. 2000;32:415-34.

31. Fredrickson LM, Anderson DH. A qualitative exploration of the wilderness experience as a source of spiritual inspiration. J Environ Psychol. 1999;19:21-39. http://dx.doi.org/10.1006/jevp.1998.0110

32. Whittington A. Girls in the woods: Exploring the impact of a wilderness program on adolescent girls' constructions of femininity. J Experiential Educ. 2006;28:285-89. http://dx.doi.org/10.1177/105382590602800317

33. Walsh MA, Russel KC. An exploratory study of a wilderness adventure program for young offenders. Ecopsychology. 2010;2:221-29.

http://dx.doi.org/10.1089/eco.2010.0035

34. Hobbs TR, Shelton GC. Therapeutic camping for emotionally disturbed adolescents. Hosp Community Psychiatry. 1972;23(10):298-301. [PMID:5070244]

35. Hyer L, Boyd S, Scurfield R, Smith D, Burke J. Effects of Outward Bound Experience as an adjunct to inpatient PTSD treatment of war veterans. J Clin Psychol. 1996; 52(3):263-78. [PMID:8835688] http://dx.doi.org/10.1002/(SICI)10974679(199605)52:3<263::AID-JCLP3>3.0.CO;2-T

36. Gelkopf M, Hasson-Ohayon I, Bikman M, Kravetz S. Nature adventure rehabilitation for combat-related posttraumatic chronic stress disorder: A randomized control trial. Psychiatry Res. 2013;209(3):485-93.

[PMID:23541513]

http://dx.doi.org/10.1016/j.psychres.2013.01.026

37. Lundberg N, Bennett J, Smith S. Outcomes of adaptive sports and recreation participation among veterans returning from combat with acquired disability. Ther Recreation J. 2011;45:105-20.

38. Cohen S, Williamson G. Perceived stress in a probability sample of the United States. In: Spacapan S, Oskamp S, editors. The social psychology of health. Newbury Park (CA): Sage; 1988.

39. Cimprich B, Visovatti M, Ronis DL. The Attentional Function Index - a self-report cognitive measure. Psychooncology. 2011;20(2):194-202. [PMID:20213858] http://dx.doi.org/10.1002/pon.1729

40. Tennessen CM, Cimprich B. Views to nature: Effects on attention. J Environ Psychol. 1996;15:77-85. http://dx.doi.org/10.1016/0272-4944(95)90016-0

41. Cimprich B. Attentional fatigue following breast cancer surgery. Res Nurs Health. 1992;15(3):199-207.

\section{[PMID:1354883]}

http://dx.doi.org/10.1002/nur.4770150306

42. Watson D, Clark LA, Tellegen A. Development and validation of brief measures of positive and negative affect: The PANAS scales. J Pers Soc Psychol. 1988;54(6):1063-70. [PMID:3397865]

http://dx.doi.org/10.1037/0022-3514.54.6.1063

43. Hughes ME, Waite LJ, Hawkley LC, Cacioppo JT. A short scale for measuring loneliness in large surveys: Results from two population-based studies. Res Aging. 2004;26(6): 655-72. [PMID:18504506] http://dx.doi.org/10.1177/0164027504268574

44. Lee RM, Robbins SB. Measuring belongingness: The Social Connectedness and the Social Assurance Scales. J Couns Psychol. 1995;42:232-41.

http://dx.doi.org/10.1037/0022-0167.42.2.232

45. Snyder CR, Sympson SC, Ybasco FC, Borders TF, Babyak MA, Higgins RL. Development and validation of the State Hope Scale. J Pers Soc Psychol. 1996;70(2):321-35.

[PMID:8636885]

http://dx.doi.org/10.1037/0022-3514.70.2.321

46. Crumbaugh JC. The Seeking of Noetic Goals Test (SONG): A complementary scale to the Purpose in Life Test (PIL). J Clin Psychol. 1977;33(3):900-907.

[PMID:893732]

http://dx.doi.org/10.1002/10974679(197707)33:3<900::AID-JCLP2270330362>3.0.CO;2-8

47. West BT, Welch KB, Galecki AT. Linear mixed models: A practical guide using statistical software. Boca Raton (FL): Chapman \& Hall/CRC Press; 2006.

48. Polak AR, Witteveen AB, Reitsma JB, Olff M. The role of executive function in posttraumatic stress disorder: A systematic review. J Affect Disord. 2012;141(1):11-21.

[PMID:22310036]

http://dx.doi.org/10.1016/j.jad.2012.01.001

49. Thomas JL, Wilk JE, Riviere LA, McGurk D, Castro CA, Hoge CW. Prevalence of mental health problems and functional impairment among active component and National Guard soldiers 3 and 12 months following combat in Iraq. Arch Gen Psychiatry. 2010;67(6):614-23.

[PMID:20530011] http://dx.doi.org/10.1001/archgenpsychiatry.2010.54

50. MacDermott D. Psychological hardiness and meaning making as protection against sequelae in veterans of the wars in Iraq and Afghanistan. Int J Emerg Ment Health. 2010;12(3):199-206. [PMID:21473370]

51. Kyriakopoulos A. How individuals with self-reported anxiety and depression experienced a combination of individual counselling with an adventurous outdoor experience: A qualitative evaluation. Couns Psychother Res. 2011;11: 120-28. http://dx.doi.org/10.1080/14733145.2010.485696 
52. Walker AJ, Onus M, Doyle M, Clare J, McCarthy K. Cognitive rehabilitation after severe traumatic brain injury: A pilot programme of goal planning and outdoor adventure course participation. Brain Inj. 2005;19(14):1237-41. [PMID:16286339] http://dx.doi.org/10.1080/02699050500309411

53. Sturm J, Plöderl M, Fartacek C, Kralovec K, Neunhäuserer D, Niederseer D, Hitzl W, Niebauer J, Schiepek G, Fartacek R. Physical exercise through mountain hiking in high-risk suicide patients. A randomized crossover trial. Acta Psychiatr Scand. 2012;126(6):467-75. [PMID:22486584] http://dx.doi.org/10.1111/j.1600-0447.2012.01860.x

54. Thomas M. The Potential Unlimited Programme: An outdoor experiential education and group work approach that facilitates adjustment to brain injury. Brain Inj. 2004; 18(12):1271-86. [PMID:15666570]

http://dx.doi.org/10.1080/02699050410001698776
Submitted for publication August 29, 2013. Accepted in revised form January 22, 2014.

This article and any supplementary material should be cited as follows:

Duvall J, Kaplan R. Enhancing the well-being of veterans using extended group-based nature recreation experiences. J Rehabil Res Dev. 2014;51(5):685-96. http://dx.doi.org/10.1682/JRRD.2013.08.0190

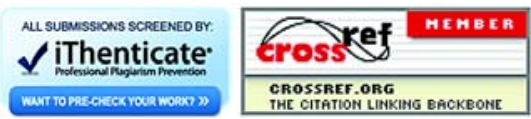

